\title{
ANÁLISE E IDENTIFICAÇÃO DO POTENCIAL INFORMACIONAL E DOCUMENTAL DOS VIDEOGAMES SOB O VIÉS DA ARQUIVOLOGIA.
}

\author{
Vanderson Monteiro Nunes \\ Graduado em Arquivologia \\ vander_ufpa@hotmail.com \\ Roberto Lopes dos Santos Junior \\ Doutor em Ciência da Informação \\ Professor da Faculdade de Arquivologia - UFPA \\ bobblopes@hotmail.com
}

Resumo

\begin{abstract}
Análise, baseado em levantamento bibliográfico e revisão de literatura em fontes secundárias, identificando o estado da arte das pesquisas ligadas a Arquivologia (e áreas correlatas como Ciência da Informação e Biblioteconomia), em relação aos videogames, discutindo as potencialidades informacionais e documentais desses suportes, e sobre as iniciativas de preservação dos jogos eletrônicos. A pesquisa inicialmente fez breve histórico sobre a evolução dos videogames, sua relação com o cinema, livros e revistas, discutindo os conceitos de documento e informação que se relacionam a essas mídias, das análises que a Arquivologia está fazendo em relação aos videogames, e uma breve abordagem sobre a preservação digital dessas mídias. A pesquisa identificou que as discussões da Arquivologia brasileira sobre a temática encontram-se em fase introdutória, sendo identificados apenas dois trabalhos na área discutindo os possíveis aspectos arquivísticos dessas mídias. Porém, as informações encontradas indicam que a temática possui potencial para posterior desenvolvimento pela Arquivologia
\end{abstract}

Palavras chave: Arquivologia. Videogames. Documento Arquivístico. Preservação.

\section{INTRODUÇÃO}

Nas últimas décadas os arquivos passaram por transformações, devido ao avanço das tecnologias da informação, que proporcionaram novas formas de criar, armazenar e utilizar documentos, no qual a demanda da sociedade pelos direitos a informação, memória e a propriedade intelectual foram intensificadas (LOPES, SANTOS, 2016).

Atualmente o conceito de memória, quando relacionado a preservação da informação, é realizada por processos de codificação, armazenamento e recuperação. Hoje em dia se fala de memória como algo

\footnotetext{
${ }^{1}$ Videogame é um programa interativo com jogos cujas imagens são apresentadas numa tela de computador ou de televisão e acessadas através de
}

"quantificável", a exemplo das memórias internas de celulares, computadores, câmeras, etc. (BEIGUELMAN, 2014).

Com o surgimento de novas tecnologias capazes de armazenar conteúdos que dizem respeito a história de uma sociedade, há de se repensar o conceito de memória no ambiente digital, não apenas como algo quantitativo, ou como um número que determina certa capacidade de armazenamento, mas também como um meio de construção da história através dos produtos culturais (BEIGUELMAN, 2014).

Podemos citar como exemplo de produto cultural resultante dos meios digitais os videogames $^{1}$, considerados, por diferentes

um controle remoto ou teclado. $O$ videogame pode ser também o aparelho que roda os jogos (console) ou os próprios jogos eletrônicos. Os videogames 
autores, artefatos culturais e econômicos, ganhando uma crescente análise na comunidade acadêmica. Segundo Aaseth (2000), o videogame é um expressivo e complexo fenômeno estético e de linguagem, que foi capaz de desenvolver, ao longo de seu curto período de existência, uma retórica própria.

Segundo Barwick, Dearnley e Muir (2011), os videogames possuem um significado cultural pois, assim como o cinema, a televisão e o rádio, os mesmos podem refletir mudanças, tendências e particularidades da sociedade contemporânea. Além das potencialidades comerciais, os jogos fazem parte da memória de muitos usuários, onde, em vários momentos, interações com amigos e familiares se deram a partir da utilização desses jogos.

Os videogames têm ganhado popularidade nas últimas décadas, visualizado atualmente com a crescente popularidade dos jogos para celular e com capacidade multiplayer ${ }^{2}$, como também na tendência conhecida como $e$-Sports (esportes eletrônicos), que consiste em competições de jogos eletrônicos (profissional ou amador), muitas vezes coordenado por diferentes ligas, onde os jogadores normalmente pertencem a equipes ou organismos "desportivos" patrocinados por organizações empresariais, transmitidas ao vivo pela internet e canais de TV, acompanhadas mundialmente por diversos telespectadores.

Dentro desse contexto do crescente reconhecimento dos videogames, surgem alguns questionamentos: Como se encontram as discussões na Arquivologia em relação a esse tipo de suporte em sua produção bibliográfica? Poderiam os videogames serem considerados "documentos arquivísticos", justificando assim sua análise pela área? Existem iniciativas práticas de tratamento e preservação dessas mídias por parte da Arquivologia?

também podem ser de diferentes tipos como, por exemplo, consoles domésticos, arcades, consoles portáteis ou jogos para computadores. < Https://www.dicio.com.br/videogame/> Acesso em: 13/02/2017

${ }^{2}$ Um jogo multiplayer é jogado por mais de um jogador simultaneamente.

${ }^{3} \mathrm{O}$ presente artigo é desdobramento do projeto de pesquisa "Preservação arquivística e os
Tais questionamentos serviram de ponto de partida para a realização desse trabalho ${ }^{3}$, que tem como objetivo identificar quais análises a Arquivologia está fazendo em relação aos videogames, discutindo as potencialidades informacionais e documentais desses suportes, e em iniciativas relacionadas a preservação dos jogos eletrônicos. $\mathrm{O}$ presente trabalho justifica-se por oferecer subsídios para maior discussão da área sobre o tema, uma vez que pesquisas abordando a relação da Arquivologia e os videogames no Brasil encontram-se escassas.

A metodologia da pesquisa foi $o$ levantamento bibliográfico, através de revisão de literatura, utilizando trabalhos e estudos existentes na Arquivologia e em áreas relacionadas, como a Ciência da Informação e Biblioteconomia, realizadas a partir dos anos 2000, tanto em material impresso quanto em formato digital. Foram consultados livros, artigos científicos e periódicos (em português e inglês), sites e blogs.

Em relação à pesquisa, inicialmente foi feito um breve histórico sobre a origem e evolução dos videogames, sua relação com a indústria cultural (cinema, livros e revistas), de aspectos documentais e informacionais que permeiam essas mídias, das análises que a Arquivologia está fazendo em relação aos videogames, e uma breve abordagem sobre as iniciativas de preservação dessas mídias.

\section{HISTÓRIA E EVOLUÇÃO DOS VIDEOGAMES $^{4}$}

A origem dos jogos eletrônicos data de meados dos anos 1940, com iniciativas isoladas que buscaram o aprimoramento de televisores para incorporação com os primeiros computadores produzidos como, por exemplo, o Eletronic Numerical Integrator and Computer (ENIAC, 1946) e o UNIVersal Automatic Computer (UNIVAC, 1950). Nos

videogames: em busca de um estado da arte", fomentado pela Universidade Federal do Pará, e do Trabalho de Conclusão de Curso "A Arquivologia e os Videogames: primeiras abordagens", defendido em março de 2017.

${ }^{4}$ As informações dessa parte foram tiradas dos trabalhos de Amorim (2006) e Bresciani (2002). 
anos 1950, o físico William Higinbotham (1910-1994), criou o Tennis for Two (1958), desenvolvido em um Osciloscópio (instrumento de medida destinado a visualizar um sinal elétrico), com o objetivo de entreter os visitantes do laboratório onde o físico trabalhava. Em 1961, estudantes do Instituto de Tecnologia de Massachusetts desenvolveram o também precursor Spacewar! consistindo em duas naves que disparavam torpedos uma à outra, com um buraco negro no centro, que deveria ser desviado para evitar danos às aeronaves.

Modelos como o Programmed Data Processor-1 (1962), e jogos como Tennis, e Chess (ambos de 1967), produzidos pelos engenheiros estadunidenses Nolan Bushnell, Ralph Baer (1922-2014) e Steve Russell, consolidaram os primeiros consoles e computadores "interativos", alguns deles patenteados em 1970. Embora primitivos e limitados, essas iniciativas serviram de base para a construção dos primeiros Arcades $^{5}$ como Computer Space (1971), Pong (1972), Death Race 2000 (1975) e Space Invaders (1978), dos primeiros consoles, com destaque para o Magnavox Odissey (1972) e Atari 2600 (1978), além da consolidação de empresas, em especial a Atari (EUA), dedicadas a confecção de fliperamas e consoles.

Marcado pela popularização dos fliperamas, surge Pac-man (1980), primeiro jogo com protagonista, premissa essa importante para sua expansão nos Estados Unidos e Ásia. Na mesma época, a japonesa Nintendo começava a erguer sua hegemonia, com seu primeiro sucesso de vendas, o Famicom de 8 bits (1983), o qual foi lançado na américa como NES (Nintendo Entertainment System). Nessa plataforma foram disponibilizados jogos como Super Mario (1985) e Donkey Kong (1983).

Enquanto a Nintendo se consolidava, sua principal rival no mercado de consoles, a SEGA, também japonesa, lançou o Master System (1985), contudo se vendo obrigada a concentrar seus esforços na criação do Mega

\footnotetext{
${ }^{5}$ Arcade ou fliperama (como é conhecido no Brasil) é um aparelho de jogo eletrônico profissional instalado em estabelecimentos de entretenimento. Compõe-se de um gabinete (caixa de madeira ou material plástico), tubo de imagem (CRT) ou monitor de vídeo, fonte de alimentação, controle(s)
}

Drive (1988), primeiro console de 16 bits. A Nintendo entrou na disputa e lançou o Super Nintendo (1990), onde enquanto o console da SEGA tinha mais jogos, o da Nintendo possuía melhores gráficos ${ }^{6}$.

Surge nos anos 1990 uma nova concorrente, a japonesa Sony, permitindo a consolidação de uma nova geração de consoles. A SEGA lançou, sem muito sucesso, o Saturn (1994), seu console de 32 bits, e a Nintendo surpreendeu lançando o Nintendo 64 (1996), com gráficos de 64 bits. Porém, o maior lançamento na época foi o console da Sony, PlayStation (1994). Por possuir grande variedade de jogos, se tornou líder de vendas, obtendo a marca de 100 milhões de unidades vendidas. Nessa época os consoles domésticos superam os Arcades, marcando a transição dos pixels para os gráficos em $3 D$.

Nos anos 2000, a Sony lança o PlayStation 2 (2000), o qual continuou o sucesso do seu antecessor e passou a ter mídias em $D V D$. Nessa época surge o Xbox (2001), lançado pela Microsoft, marcando a era de continuidade da evolução gráfica e realismo nos jogos. Com o surgimento do Nintendo Wii (2006) e do sensor de movimento Kinect para Xbox 360 (2010), houveram inovações na maneira de interagir com os videogames, agora com o jogador podendo usar movimentos corporais para comandar o jogo.

A mais recente geração de consoles se resume a três lançamentos: PlayStation 4 (2013), da Sony, Wii U (2012), da Nintendo, e Xbox One (2013), da Microsoft. Todos os consoles com processadores capazes de reproduzir gráficos visuais e efeitos sonoros cada vez mais realistas.

Com a popularização dos computadores domésticos nos anos 1980, assim como o desenvolvimento da internet e o surgimento das lan-houses nos anos 1990, vários jogos foram desenvolvidos, como os de simulação "multi-plataformas", "jogos multijogador", ou "jogos de interpretação de personagens online para múltiplos jogadores" (em inglês MMORPG). A partir de 1995, Doom 2 e Quake

de jogo e sistema de jogo. https://www.arcademuseum.com/ Acesso: 16/03/2016

${ }^{6}$ Mais informações sobre esse período identificado como "guerra dos consoles" pode ser encontrado em Harris (2015). 
destacam-se como jogos que fizeram sucesso acompanhando a evolução da internet. Outros títulos encontrariam nesses meios o local ideal para seu desenvolvimento, como exemplos bem-sucedidos Counter-Strike (1999), The Sims (2000), Second Life (2003), World of Warcraft (2005) e Minecraft (2011).

\section{OS VIDEOGAMES E A INDÚSTRIA CULTURAL}

Segundo Aarseth (2000), os videogames são atualmente produtos da indústria cultural $^{7}$ de mais rápido crescimento, com um volume de negócios anual que, em alguns momentos, ultrapassa a indústria cinematográfica nos EUA. Exemplos desse crescimento são vistos com o número de vendas do jogo Grand Theft Auto $V$, que arrecadou 1 bilhão de dólares, e do console Playstation 2 , que obteve 157 milhões de unidades vendidas ${ }^{8}$.

Ainda nos EUA, cita-se a crescente inclusão dos videogames em centros de arte e cultura, fato esse visualizado no ano de 2012, com parte do Museu de Arte Moderna (MoMA) de Nova York dedicada aos videogames. A atual curadora do museu, Paola Antonelli, estabeleceu o videogame como um elemento importante da cultura pop ${ }^{9}$ norte americana.

Segundo essa perspectiva, os videogames podem estar inseridos na

\footnotetext{
${ }^{7}$ Segundo Coelho (2003, p. 8), "Indústria cultural é um daqueles objetos de estudo que se dão a conhecer às ciências humanas antes por suas qualidades indicativas, ou aspectos exteriores, do que por sua constituição interior, estrutural". Para o autor, "indústria cultural" e "meios de comunicação" são interpretados como sinônimos e interdependentes. Portanto, para que a indústria cultural exista é necessário que haja o "meio de comunicação" para que atinja o seu objetivo, neste caso a "cultura de massa".

8 'GTA V' quebra seis recordes de vendas e entra para o Guiness - G1 Tecnologia e Games; 8/10/2013. Disponível em:
} http://g1.globo.com/tecnologia/games/noticia/20 13/10/gta-v-quebra-seis-recordes-de-vendas-eentra-para-o-guinness.html Acesso em cultura popular pois, ocasionalmente, influenciam outras mídias e meios de comunicação de massa. Shaw (2010), ao referir-se aos estudos feitos em relação à "cultura dos videogames", considera que os mesmos fazem parte de um segmento articulado a uma cultura dominante, e não uma manifestação isolada. A autora afirma que

[...] a cultura dos jogos [...] permeiam a educação, as tecnologias móveis, os displays de museus, as funções sociais, as interações familiares e os locais de trabalho. Eles são jogados por muitas, se não todas, as idades, sexualidades, religiões e nacionalidades e todos os gêneros. Nem todos esses tipos de "jogar" e de jogadores podem ser englobados num estudo sobre uma comunidade isolada (SHAW, 2010, p. 14).

Os videogames, desde a década de 1990 , dialogam com o cinema e a literatura. Um sinal dessa aproximação são atores de Hollywood emprestando suas vozes a diferentes títulos, como é o caso de Kevin Spacey, vencedor do Oscar em 2000. Em 2014, Spacey interpretou o protagonista do jogo Call Of Duty: Advanced Warfare, lançado para as plataformas da Sony (Playstation 3 e 4), Microsoft (Xbox 360 e Xbox One) e PC. Além de Spacey, outros atores participaram de projetos ligados aos videogames: Ray Liotta, em 2003 quando interpretou Tommy Vercetti em Grand Theft Auto: Vice City; Neil Patrick Harris, com o personagem Peter Parker, no game Spider Man: Shattered Dimensions, em 2010; além de

05/01/2016; GONÇALVES, J. Confira os 5 videogames mais vendidos da história - Olhar Digital UOL; 04/01/2016. Disponível em: http://olhardigital.uol.com.br/noticia/confiraos-5-videogames-mais-vendidos-dahistoria/54084 Acesso em 05/01/2016 6 Disponível em: https://www.moma.org/explore/inside_out/2012 /11/29/video-games-14-in-the-collection-forstarters/ Acesso em: 11/02/2016

9 A cultura pop pode ser entendida como o conjunto de ideias, perspectivas, atitudes, imagens, e outros fenômenos que estão inseridos em uma tendência ou moda da cultura de uma sociedade. Influenciada pelos meios de comunicação de massa, essa coleção de ideias permeia a vida cotidiana da sociedade (COELHO, 2003). 
atores como Christopher Walken, Charlize Theron, Patrick Stewart, Hugh Jackman, Megan Fox, Kiefer Sutherland, entre outros. ${ }^{10}$

Desde meados dos anos 1990 foram produzidos filmes baseados em jogos, geralmente, embarcando no sucesso dos títulos clássicos ou populares. Alguns exemplos que podem ser citados ${ }^{11}$ :

- O primeiro filme baseado em uma história de videogame foi Super Mario Bros da empresa Nintendo, em 1993. No papel de Mario está o ator Bob Hoskins. A bilheteria não cobriu o custo da produção, com um prejuízo de US\$ 20 milhões.

- O jogo Resident Evil, originalmente lançado em 1996 pela empresa Capcom, deu origem a uma série de filmes de terror de sucesso. A atriz Milla Jovovich interpreta Alice, que tem a missão de enfrentar uma horda de cientistas transformados em zumbis.

- O jogo Prince of Persia, série de jogos de ação-aventura da empresa Ubisoft, teve sua versão cinematográfica em 2010, Príncipe da Pérsia - As Areias do Tempo, faturando US\$ 335 milhões. O longa foi estrelado pelo ator Jake Gyllenhaal no papel principal.

$\mathrm{Na}$ indústria literária também temos a influência dos games, com livros publicados sobre jogos. Alguns exemplos que podem ser citados $^{12}$ :

- World of Warcraft, que é um $M M O R P G$ da produtora Blizzard, virou o livro World of Warcraft - Marés de Guerra, Bestseller nos Estados Unidos.

- God of War, série de jogos da Sony, que ganhou popularidade graças a sua temática mitológica e seu personagem Kratos, também ganhou um livro, God of War: A História Oficial que deu origem ao jogo, escrito pelos norte-americanos Matthew Stover e Robert E.

\footnotetext{
${ }^{10}$ Atores de Hollywood estão sendo atraídos para o mundo dos games" Oficina da Net: 24/11/2014. Disponível em:

https://www.oficinadanet.com.br/post/13702 Acesso em: 24/11/2016

${ }^{11}$ Relembre dez filmes baseados em videogames famosos O Globo, 2015. Disponível em: http://oglobo.globo.com/cultura/relembre-dezfilmes-baseados-em-videogames-famosos$\mathbf{7 4 5 7 6 3 5}$ / Acesso em: 13/01/2017

${ }^{12}$ Conheça 8 games que viraram livros, Marketing \& Games, 2014. Disponível em: http://www.marketingegames.com.br/8-gamesque-viraram-livros/ Acesso em: 10/10/2016
}

Vanderman. Apesar do título, o livro conta detalhes que ficaram subtendidas na história do jogo.

- Assassin's Creed é uma série de jogos de ação-aventura da empresa Ubisoft, criada por Patrice Marla Desilets, centrada na batalha travada entre assassinos e templários ao longo da história. $O$ game teve uma série de 6 livros lançados: Assassin's Creed: Renascença, Assassin's Creed: Irmandade, Assassin's Creed: A Cruzada Secreta, Assassin's Creed: Revelações, Assassin's Creed: Renegado e Assassin's Creed: Bandeira Negra.

Além dos livros, existem revistas especializadas em games, tanto para os que curtem jogos mais antigos ou clássicos, que é o caso dos chamados retro gamers ${ }^{13}$, quanto para os que curtem estar antenados no universo dos videogames.

No Brasil, a Editora Europa é responsável pela publicação da revista Old!Gamer, primeira revistadedicada aos videogames clássicos. É uma publicação que retrata o passado dos games, com matérias sobre consoles clássicos como o SNES, Atari, Master System, Neo-Geo, inclusive usando trechos de revistas antigas em uma seção especial. Outro exemplo é a Nintendo World, revista brasileira com especialidade em notícias e estratégias sobre jogos da Nintendo com sua primeira edição lançada em $1998^{14}$. A Editora Europa também publica regularmente revistas especializadas aos consoles PS4 e Xbox One, como, por exemplo, os guias oficiais Playstation Brasil e Xbox Brasil, que possuem as informações mais atualizadas a respeito desses consoles.

Existem também sites com conteúdo voltado exclusivamente para jogos e consoles. Um dos mais famosos é o portal americano,

\footnotetext{
${ }^{13}$ Retrogaming (em português, jogos retro), é um movimento relacionado com o colecionar ou jogar, videogames do passado, normalmente derivados de sistemas antigos, tanto de computadores e consoles, como de máquinas de árcade [...] os participantes desse movimento são normalmente conhecidos na Europa como Retro Gamers, enquanto nos EUA são designados através dos termos Classic Gamers, ou Old-School Gamers. <http://gamescriticism.org/articles/heineman-11/> Acesso em 12/03/2017

${ }^{14}$ Disponível

http://nintendoworld.com.br/nw/nintendoworld-zero/
} 
que recentemente ganhou uma versão brasileira, IGN. O portal foi formado pela união de seis sites, em 1996, com conteúdo de diversas plataformas. Outro portal é o GameSpot, que traz notícias, análises, downloads e outras informações relevantes sobre os jogos lançados no mercado. Foi criado em 1996, e é um dos 200 sites mais acessados do mundo, de acordo com o serviço Alexa internet. ${ }^{15}$

Além das influências no cinema e literatura, os pesquisadores estão estudando a importância dos videogames para a educação, entendendo-o como uma mídia ou meio de comunicação (AZEVEDO JÚNIOR, 2014). Para Lucia Santaella (2009, p.55), pesquisadora brasileira da linguagem e semiótica, "os games alcançaram o ponto mais sofisticado de exploração diversificada dos tipos de linguagem, e por essa razão devem ser cada vez mais investigados cientificamente". Ainda segundo a pesquisadora "(...) os games conquistaram espaço na cultura de massa, assim como teve sua vez a fotografia, o jornal, o rádio, a televisão e o cinema" (SANTAELLA, 2009, p. 55).

James Paul Gee, pesquisador norteamericano conhecido por trabalhar aprendizagem com jogos de videogame, os identifica como uma ferramenta útil de aprendizagem, apontando para formas em que, quando jogado em um ambiente que promove o pensamento crítico, os jogos podem tornarse eficientes ferramentas de ensino, ganhando cada vez mais reconhecimento pela comunidade acadêmica:

Indeed, the argument that video and computer games are superior to school in helping children learn is gaining currency in academic circles. Claimed benefits include improved problem-solving, mastery of scientific investigation and the ability to apply information learned to real-life situations (GEE, 2006, p. 939).

Feita essa contextualização dos videogames no cenário contemporâneo, nos tópicos a seguir, o trabalho focou nos aspectos informacionais e documentais dos jogos eletrônicos, além de breve análise sobre o potencial de preservação desses suportes.

\section{DISCUTINDO O POTENCIAL INFORMACIONAL E DOCUMENTAL DOS VIDEOGAMES}

Antes da análise sobre o potencial informacional e documental dos videogames, inicialmente será feito uma breve análise sobre os conceitos informação e documento.

Segundo o Dicionário Brasileiro de Terminologia Arquivística, documento é definido como uma "(...) unidade de registro de informações, qualquer que seja o suporte ou formato" (2005: p. 73; 107), caracterizando-se por ser um “(...) elemento referencial, noção, ideia ou mensagem" (2005: p 107). Segundo Bellotto (2002, p.22), “(...) uma informação registrada em suporte de qualquer tipo, caracteriza-se por documento". Sobre o conceito de informação, Bellotto (2002, p. 22) afirma que, “(...) é a ação e também efeito de comunicar dados; qualquer atributo do pensamento humano sobre a natureza e a sociedade, desde que verbalizada ou registrada". Para isso, a informação passa por um processo de comunicação, até chegar ao receptor que toma conhecimento dela, usa e a consome.

Nesse aspecto, um dos poucos consensos ao qual as literaturas brasileira e internacional partilham encontra-se na classificação dos videogames como documentos eletrônicos e digitais. Segundo Schafer e Constante (2012, p.111), documento digital é o "documento codificado em dígitos binários, acessível por meio de sistema computacional", enquanto documento eletrônico configurase como "gênero documental integrado por documentos em meio eletrônico ou somente acessível por equipamentos eletrônicos, como cartões perfurados, disquetes e documentos digitais.".

Segundo essa perspectiva, muitos dos consoles antigos de videogames podem ser

${ }^{15}$ Informações obtidas no site

http://www.alexa.com/siteinfo/gamespot.com 
identificados como documentos eletrônicos, por "serem acessíveis e interpretáveis por meio de um equipamento eletrônico (filmadora, computador, videocassete), registrados e codificados em forma analógica ou em dígitos binários", e os jogos podem ser classificados como documentos digitais, sendo um "documento eletrônico caracterizado pela codificação em dígitos binários e acessado por meio de sistema computacional" (SCHAFER, CONSTANTE, 2012, p.111). No caso dos jogos antigos, a maioria se encontra registrado em suporte analógico, como, por exemplo, nos chips encontrados nos cartuchos onde os jogos são armazenados. Atualmente, alguns consoles portáteis, como o PS Vita da Sony e o Nintendo 3DS, utilizam uma espécie de "mini cartucho" para gravar os jogos, porém aceitando títulos tanto em mídia física quanto digital.

Rondinelli $(2011,2013)$ reflete sobre o conceito de documento arquivístico frente à realidade digital, afirmando que, a partir da junção dos conceitos documento, documento arquivístico e documento digital, chega-se ao termo documento arquivístico digital, definido como:

[...] unidade indivisível de informação constituída por uma mensagem fixada num suporte (registrada), com uma sintática estável [...] produzido e/ou recebido por uma pessoa física ou jurídica, no decorrer das suas atividades [...] codificado em dígitos binários e interpretável por um sistema computacional, em suporte magnético, ótico ou outro" (RONDINELLI, 2011, p. 227).

Nessa ótica, podemos identificar que os videogames possuem características documentais, pois nessa mídia estão registrados atributos do pensamento humano sobre a natureza e a sociedade, transmitidas para o receptor, nesse caso o jogador, que irá consumir essa informação. Segundo essa perspectiva, os videogames caracterizam-se também por serem resultado da capacidade de

\footnotetext{
${ }^{16}$ Dados estruturados e codificados, que descrevem e permitem acessar, gerenciar, compreender, e/ou
}

expressão humana, assim como filmes, músicas, quadros, livros e outras formas de expressar sentimentos e ideias, onde cada jogador irá interpretar o jogo de forma diferenciada (COUTO; MATSUGUMA, 2012).

Segundo Rockembach (2015), um dos aspectos da Arquivologia enquanto disciplina se estabelece no caráter probatório dos documentos de arquivo, que através de outras disciplinas, como a Diplomática, buscam a autenticidade desses documentos. Um dos elementos constituintes desse caráter probatório é a evidência da informação, que em ambiente digital possui três esferas: indício, evidência e prova.

Em meio digital, a informação como indício é usada a partir dos rastros deixados pelo usuário, que podem ser tanto pelos metadados $^{16}$, que são resultantes do registro feito automaticamente pelo Software através da interação usuário - sistema, como pelos Cookies, rastros deixados pelo usuário através do histórico de navegação (ROCKEMBACH, 2015: p. 54- 55). Segundo essa perspectiva, a informação como indício também poderia ser visualizada nos videogames, uma vez que existem jogos que usam mecânicas para jogar online, onde os jogadores geralmente precisam fazer algum tipo de cadastro ao ingressar em algum servidor, deixando assim informações na rede.

Em relação a evidência, Gil (1996, p. 55) afirma que "[...] o pensamento da evidência constrói-se sobre o sistema percepção linguagem". Segundo o autor, o uso dos sentidos humanos para identificar a expressão dessa realidade, captada por meio da linguagem, são os principais canais da evidência da informação. Os videogames, segundo essa perspectiva, podem possuir tais características, uma vez que são resultado da expressão humana, seja através da retratação de um momento histórico da sociedade, como é o caso da franquia de jogos Medal of Honor, seja em jogos que simulam acontecimentos simples do cotidiano, como é o caso do título The Sims.

Por fim, temos a informação como prova, que, no âmbito digital, depende de uma validação externa, regulamentada em lei ou

preservar outros dados ao longo do tempo (ARQUIVO NACIONAL, 2005). 
definida pela justiça, que configurará uma jurisprudência sobre o assunto. Segundo Rockembach (2015), "todo processo de fazer prova implica uma certificação ou validação". No que diz respeito à certificação ou validação nos videogames, os fabricantes de consoles e jogos investem em tecnologia para combater a pirataria e o uso indevido de suas obras. A Nintendo, por exemplo, em seus cartuchos do console Nintendo 64, usava um Hardware adicional para programar mecanismos de proteção contra cópia (GUTTENBRUNNER et al. 2010).

Outra questão importante no âmbito da prova em meio digital é o direito autoral, onde o autor de determinada informação pode exercer direitos intelectuais e/ou financeiros. (ZANAGA; LIESENBERG, 2008, p. 57).

Nesse sentido, os videogames também possuem questões jurídicas e legais em seu desenvolvimento. Os fabricantes do Hardware original geralmente mantêm informações de desenvolvimento de seus jogos em sigilo. Produtores de determinados jogos (software) podem ser diferentes dos fabricantes do console (Hardware), e possuir os direitos sobre o código do videogame e limitar seu uso a um determinado console, de maneira que, para transferir o código do videogame para diferentes meios de comunicação, é necessária a aprovação de todos os titulares de direitos envolvidos no jogo (GUTTENBRUNNER et. al., 2010). Essas questões tornam-se um dos desafios da preservação digital nos videogames, uma vez que essas informações e códigos são importantes para obtenção de dados fora da mídia original.

Segundo Rockembach (2015), o uso e gestão das dimensões da informação em ambiente digital fazem parte das atividades dos profissionais da informação. É algo com que as disciplinas que elegem a informação como objetos científicos, a exemplo da Arquivologia, trabalham de forma constante.

Conforme analisado, os videogames possuem aspectos documentais $\mathrm{e}$ informacionais, podendo assim considerá-los

\footnotetext{
${ }^{17}$ Nessa pesquisa foram utilizadas as apresentações G.A.M.E. - HISTÓRIA: Videogames e os Documentos Audiovisuais, apresentado no Arquivo Nacional em outubro de 2014, disponível em: https://prezi.com/dpdxq0upprso/game-historiavideogames-e-os-documentos-audiovisuais/
}

objetos passiveis de análise pela arquivologia. Apesar dessa identificação preliminar, percebeu-se que discussões mais aprofundadas sobre o pretenso potencial arquivístico desses objetos e sua inclusão em acervos documentais, encontram-se ainda pouco exploradas.

Exemplos desse tipo de análise podem ser visualizados em artigos dos autores Valle (2003), Hedstrom e Lee (2002), Duarte (2014) e Whedbee (2016), que indicam a necessidade da inclusão dos jogos eletrônicos em acervos relacionados a bibliotecas, arquivos e museus, considerando os consoles, computadores e jogos, "artefatos eletrônicos/digitais" ou "artefatos históricos" que passam a ser classificados como importantes objetos de informação e memória, possuindo uma gama de dados que não podem ser ignorados pela sociedade contemporânea.

Focando na realidade arquivística brasileira, Marcelo Kosawa, professor do curso de Arquivologia pela Universidade Federal do Amazonas, foi um dos poucos profissionais da área a discutir a possível relação entre Arquivologia e os videogames. Segundo o autor, em apresentações realizadas entre 2013 e $2015^{17}$, os videogames podem ser incluídos no âmbito dos documentos audiovisuais, assim como os relacionados aos discos, rádio, televisão e outras mídias ligadas aos "arquivos especiais". O autor destaca três temáticas que poderiam servir de base entre a Arquivologia e os jogos eletrônicos: multilinearidade (navegação exploratória, autodirigida, sendo o utilizador a determinar o seu próprio caminho de leitura da informação), plataformas (modelos de consoles), e acesso a informação e interatividade.

Outro exemplo é o trabalho de conclusão de curso de Rafael Rocha, da Universidade Federal do Estado do Rio de Janeiro, que discutiu as possíveis relações entre os videogames e os arquivos, realizando uma revisão de conceitos na literatura acadêmica e legislação brasileira, a fim de verificar se os videogames poderiam ser considerados

acesso em 05/03/2016; e no curso Jogos eletrônicos: Do documento ao conhecimento histórico, realizado em 2014, disponível em: https://prezi.com/x8pg4ozb23m0/jogoseletronicos/ Acesso em: 25/06/2016 
documentos arquivísticos. Com base na revisão conceitual na área, o autor constatou que não há limitação nos conceitos de documento arquivístico que excluam os videogames, desde que as características deste tipo de documento estejam presentes no suporte (ROCHA, 2016).

\section{PRESERVAÇÃO DIGITAL DOS VIDEOGAMES ${ }^{18}$}

A questão da aplicação das novas tecnologias da informação e dos computadores aos arquivos, bem como a gestão e preservação de documentos eletrônicos e digitais, está sendo discutido pela arquivologia desde os anos 1990, em artigos, comunicações e livros da área (THOMAZ, 2006).

Segundo Boeres e Arellano (2005, p. 2), a preservação digital constitui-se em "“[...] processo distribuído que envolve o planejamento, alocação de recursos e aplicação de métodos e tecnologias para assegurar que a informação digital de valor contínuo permaneça acessível e utilizável". Em relação às estratégias de preservação digital, Schafer e Constante (2012, p. 114-118) agruparam-nas em três principais: migração, ou "procedimento de transferência do objeto digital para um suporte/plataforma (podendo abranger hardware, software e formatos) de geração tecnológica subsequente, permitindo que as informações estejam acessíveis ao longo do tempo"; emulação, que "[...] baseiase na utilização de um software (denominado emulador) que tem a função de reproduzir o comportamento de um determinado hardware e/ou software em uma plataforma com a qual não era compatível"; e encapsulamento, que "(...) visa à preservação conjunta do objeto digital, com as informações necessárias ao futuro desenvolvimento de funcionalidades para sua conversão e visualização."

Com o reconhecimento artístico e cultural dos videogames, a partir dos anos 2000, a preservação digital dos videogames passou a ser tema de pesquisas, além de se tornar foco de iniciativas práticas visando a preservação dessas mídias. Segundo Guttenbrunner,

\footnotetext{
${ }^{18}$ Nesse artigo, em relação a preservação digital dos jogos eletrônicos, optou-se por uma abordagem mais geral, focando em análises sobre o potencial de preservação desses suportes, e em inciativas
}

Becker e Rauber (2010) os videogames são considerados "arte interativa digital", fazendo parte de nossa herança cultural, e, portanto, devendo ser preservados para futuras gerações.

Ainda segundo os autores, a preservação das características intrínsecas (bits, códigos, sistemas, estrutura interna do jogo) e extrínsecas (regras, nível de jogabilidade) dos videogames se faz necessária, pois, com o avanço da tecnologia dos jogos e a evolução dos consoles, ambos os suportes, após certo período, acabam ficando obsoletos, com o risco da perda de informação desse material.

Newman (2011) destaca a quantidade considerável de jogos que, por não conseguirem retorno comercial ou um "status Cult" por parte dos consumidores, desaparecem, deixando poucos registros de sua existência e funcionalidade. $\mathrm{O}$ autor afirma que dois problemas surgem simultaneamente sobre essa questão: os consoles de gerações anteriores ficam em segundo plano, postos apenas como objeto de curiosidade de um público específico em espaços localizados, e a obsolescência, onde a preocupação do contínuo funcionamento desses equipamentos não seja perdida com o passar do tempo.

Gooding e Terras (2008) listaram e discutiram as principais temáticas que permeiam os estudos de preservação digital nos videogames, focados nos aspectos técnicos e culturais nas etapas de desenvolvimento, produção e comercialização de determinado equipamento ou jogo. Os autores também abordam questões sobre de que forma ocorrem as iniciativas (por vezes deficitárias) de organismos públicos e das empresas de design dos jogos na salvaguarda dos mesmos. Os autores também abordam a dificuldade do campo arquivístico em tratar de forma quantitativa as perdas resultantes de um processo ineficiente de preservação digital, resultando no desaparecimento de jogos e consoles, além de uma análise sobre a disponibilidade do hardware e software; o potencial de preservação em determinado jogo; disponibilidade de se obter jogos em estabelecimentos comerciais; e a perda de metadados dos jogos na internet.

práticas localizadas. Informações mais detalhadas sobre as estratégias de preservação realizadas nessas mídias podem ser vistas em Santos Junior (2016) e Santos Junior e Nunes (2016). 
Em relação às estratégias de preservação no âmbito dos videogames, os autores Guttenbrunner, Becker e Rauber (2010) sugerem a construção de museus ou espaços tecnológicos; identificar a obsolescência dos consoles e cartuchos; a consolidação das estratégias de migração e emulação como as principais a serem consideradas pelos arquivistas ou profissionais de informação que irão realizar esses procedimentos; dados sobre o contexto e jogabilidade ${ }^{19}$ dos títulos; e dos custos dos projetos de preservação digital. Os autores listaram também os principais desafios encontrados nas práticas de preservação digital nos videogames: análise sobre os códigos e particularidades dos consoles; estudo sobre o conteúdo dos cartuchos, CD-ROM e DVDs; análise sobre aspectos de interação além dos consoles e cartuchos como, por exemplo, itens extras (armas, diferentes tipos de joystick) para serem usados nos jogos; título disponível para mais de um jogador; o aparelho de televisão onde os jogos eram exibidos; e os aspectos legais envolvendo a produção e comercialização do jogo (quem fez o jogo e quem possui os direitos comerciais do mesmo).

No que diz respeito às iniciativas práticas no âmbito da preservação dos videogames, alguns exemplos podem ser visualizados na Biblioteca Nacional do Congresso Norte Americano, que financiou o Programa de Infraestrutura de Informação Nacional Digital (NDIIP) no período entre 2007 e 2010; além do Instituto de Serviços de Museus e Bibliotecas (IMLS) estadunidense, que analisou a produção de videogames e o seu processo de criação, também entre 2007 e 2010. Outro exemplo é o "National Videogame Museum" (Museu Nacional do Videogame), também localizado nos $\mathrm{EUA}^{20}$, que visa preservar a história da indústria dos videogames, arquivando não apenas os artefatos físicos, como também as informações por trás de sua criação.

Newman (2009; 2011) fez uma análise das iniciativas de preservação realizados pela

\footnotetext{
${ }^{19}$ Em inglês gameplay ou playability, é um termo utilizado na indústria dos jogos eletrônicos para descrever a facilidade na qual o jogo pode ser jogado (<https://en.wikipedia.org/wiki/Gameplay> Acesso em: 13/03/2017).
}

"National Videogame Archive" (Arquivo Nacional do videogame), em atividade desde 2008 na Inglaterra, destacando que os projetos da instituição oferecem informações úteis para as práticas de emulação, encapsulamento e migração dos jogos eletrônicos. Porém, critica que algumas dessas iniciativas podem produzir informações úteis para pesquisadores e acadêmicos, mas não necessariamente para os usuários desses jogos ou ao público leigo.

No Brasil, a (praticamente) única iniciativa prática voltada à preservação da memória dos videogames é a do "Museu do videogame Itinerante", pioneiro do gênero no país, reconhecido pelo IBRAM (Instituto Brasileiro de Museus). Projeto iniciado através da coleção pessoal do curador Cleidson Lima, localizado no Mato Grosso do Sul, possui mais de 200 consoles e seis mil jogos em seu acervo. Um dos diferenciais do Museu é que, além de conhecer consoles e jogos raros, os visitantes podem jogar em alguns modelos. O Museu não possui sede fixa, e desde 2015, realiza exposições em diferentes cidades Brasileiras. ${ }^{21}$

\section{CONSIDERAÇÕES FINAIS}

A presente pesquisa buscou identificar, a partir de revisão de literatura, o potencial documental e informacional dos videogames, além de informações sobre a preservação desses suportes.

Inicialmente foi percebido que, além dos diversos aspectos relacionados a memória que permeiam os videogames, cita-se a inclusão dessas mídias numa realidade ligada à cultura pop e indústria cultural, possuindo uma gama de dados que não podem ser ignorados pelos profissionais da informação. O crescimento de sua indústria e o reconhecimento do seu significado para a sociedade contemporânea fizeram com que os videogames passassem a ser objeto de estudo pela comunidade acadêmica, através do crescente número de artigos e pesquisas relacionados ao tema.

Porém, quando se trata de discutir os aspectos arquivísticos dos videogames, ou

\footnotetext{
${ }^{20}$ http://www.nvmusa.org/ acesso em 03/02/2017

${ }^{21}$ www.museudovideogame.org acesso em 03/02/2017
} 
seja, analisar os videogames enquanto documento de arquivo ou objetos informacionais, as pesquisas se encontram ainda à guisa de maior aprofundamento, apesar de algumas análises, ligados, por exemplo, aos conceitos de documento digital e eletrônico e dos elementos informacionais de indicio, evidência e prova indicarem promissores caminhos de análise sobre os videogames. As discussões no âmbito da Arquivologia brasileira encontram-se em fase introdutória, sendo identificados apenas dois trabalhos na área discutindo os possíveis aspectos arquivísticos dessas mídias. Porém, as informações encontradas indicam que a temática possui potencial para posterior desenvolvimento pela área.

Em relação a preservação eletrônica e digital, a bibliografia mostra-se mais ampla, devido, em parte, as iniciativas práticas e a consolidação de espaços dedicados ao armazenamento e divulgação dessas mídias. No cenário nacional, foi percebido que iniciativas por parte da Arquivologia ou outros campos no tratamento dos videogames são escassos, com exceção do Museu do Videogame Itinerante.

Buscou-se, com esse trabalho, contribuir com a discussão sobre a relação da Arquivologia e os videogames. Pretende-se, como consequência desta pesquisa, a continuidade da construção de um referencial teórico, servindo de base para a produção científica sobre o tema, pretendendo assim a troca de experiência e informações com pesquisadores e profissionais ligados a arquivologia e áreas correlatas.

Recebido em: 12/04/2017

Aceito em definitivo em: 22/05/2017

\section{ANALYSIS ABOUT THE INFORMATIONAL AND DOCUMENTAL POTENTIAL OF VIDEOGAMES BY ARCHIVAL SCIENCE APPROACH}

\section{Abstract}

Analysis, based on literature review of secondary sources, identifying, preliminarily, the researches produced by Archival Science (and the correlated areas, as librarianship and Information Science) about videogames, focused on the documentary and informational aspects present in this media, and the practical initiatives about their preservation. Initially, it was made an historical analysis about the origins and development of the electronic games, their relationship with cinema, books and HQs, the documental characteristics of this media, the approach made by Archival Science about Videogames, and the theoretical and practical aspects of electronic games preservation. This research found that the Archival Science produced works suggesting the preservation of videogames, despite of some objectives and procedures that have consolidated the proximity of Archival Science and this kind of media that are still in discussion, with only two works discussing this proximity located in Brazilian literature. This study also indicates that the topic has potential to be expanded in future researches produced by the Archival Science field.

Keywords: Archival Science; Videogames; Archival document; Preservation

\section{REFERÊNCIAS}

AZEVEDO JÚNIOR, M. Os games no ensino de história: problematizando a história escolar com a ajuda dos jogos eletrônicos. In: MOURA, C. B.; AZEVEDO JUNIOR, M. (Org.). A Escola do Século XXI: reflexões e implicações para as práticas docentes. Natal: 
Edunp - Editora da Universidade Potiguar, 2014, p. 31-53.

ARQUIVO NACIONAL. Dicionário Brasileiro de Terminologia Arquivística. Rio de Janeiro: Arquivo Nacional, 2005.

AMORIN, A. A origem dos jogos eletrônicos. São Paulo: EDUSP, 2006.

ARANHA, G. O processo de consolidação dos jogos eletrônicos como instrumento de comunicação e de construção de conhecimento. Ciências \& Cognição; v. 3, p. 21-62, 2004.

AARSETH, E. Allegories of space: The Question of Spatially in Computer Games. Cybertext Yearbook, p. 152 - 171, 2000. Disponível em: < http://cybertext.hum.jyu.fi/articles/129.pdf > Acesso em: 20/02/2017.

BEIGUELMAN, G. Reinventar a memória é preciso. In: BEIGUELMAN, G.; MAGALHÃES, A.G. (Org.). Futuros Possíveis: Arte, Museus e Arquivos Digitais. São Paulo/ Petrópolis: Edusp, 2014, p. 12-31.

BOERES, S. A. A.; ARELlANO, M. A. M. Políticas e estratégias de preservação de documentos digitais. In: Encontro Nacional de Ensino e Pesquisa em Informação (CINFORM), 6., Salvador, 2005. Anais Disponível em: <http://www.cinform.ufba.br/vi_anais/docs/S oniaMiguelPreservacaoDigital.pdf > Acesso em 25/04/2016.

BELlOTTO, L. H., Arquivística: objetos, princípios e rumos. Associação de Arquivistas de São Paulo, 2002. P. 22-25, Disponível em: https://pt.scribd.com/doc/51319150/BELLOT TO-Heloisa-Liberalli-Arquivistica-objetosprincipios-e-rumos-Sao-Paulo-Associacao-deArquivistas-de-Sao-Paulo-2002 Acesso em 20/06/2016.
BRESCIANI, A. A. A guerra dos botões: a estética da violência nos jogos eletrônicos. Relatório de pesquisa. Curso em Ciências Sociais. Faculdade de Filosofia e Ciências de Marília, Universidade Estadual Paulista, 2002.

COUTO, P. V.; MATSUGUMA, R. V., Videogames como meio de transmissão de cultura, XI SBGames, Brasília, p. 147-150, 2012. Disponível em: <http://sbgames.org/sbgames2012/proceeding s/papers/cultura/C_S6.pdf> Acesso em 25/04/2016.

COELHO, T. O que é indústria cultural. São Paulo: Brasiliense, 2003.

DUARTE, L. S. R. Videogames vistos segundo a Informação, Memória e Documento: o que ele é e como somos afetados por ele. In: ENCONTRO REGIONAL DOS ESTUDANTES DE BIBLIOTECONOMIA, DOCUMENTAÇÃO E GESTÃO DA INFORMAÇÃO DO NORDESTE (EREBD), 17., Fortaleza, 2014. Anais...

GEE, J. P.; Videogames: Do they have educational value? Congressional Quarterly Researcher, v.16, n. 40, p. 937-960, 2007.

GOODING, P; TERRAS, M. 'Grand Theft Archive': a quantitative analysis of the current state of computer game preservation. The International Journal of Digital Curation, v3, n.2, 2008.

GUTTENBRUNNER, M.; BECKER, C; RAUBER, A. Keeping the game alive: Evaluating strategies for the preservation of console video games. The International Journal of Digital Curation, v. 5, n.1, 2010.

HARRIS, B. J. A guerra dos consoles: Sega, Nintendo e a batalha que definiu uma geração. Rio de Janeiro: Intrínseca, 2015.

HEDSTROM, M.; LEE, C.A. Significant properties of digital objects: Definitions, applications, implications. In: CONFERENCE OF THE DIGITAL LIBRARY 
FEDERATION. Proceedings... p. 218-223, 2002.

LOPES, A. S. P.; FLORES, D. Patrimônio documental e a preservação digital em longo prazo. Acervo, v. 29, n.1, p.178-188, 2016.

NEWMAN, J. (Not) Playing Games: PlayerProduced Walkthroughs as Archival Documents of Digital Gameplay, The International Journal of Digital Curation, v.2, n.6, 2011.

NEWMAN, J. Save the Videogame! The National Videogame Archive: preservation, supersession and obsolescence, M/C Journal, v.12, n.3, 2009.

ROCKEMBACH, M., Evidência da informação no contexto dos arquivos digitais, PontodeAcesso, Salvador, v. 9, n. 2, p. 50-64, 2015.

RONDINELLI, R. C. O Conceito de documento arquivístico frente à realidade digital: uma revisitação necessária. Tese (Doutorado em Ciência da Informação) Universidade Federal Fluminense, Niterói, 2011. Disponível em: http://docplayer.com.br/4637308-Rosely-curirondinelli.html Acesso em: 10/01/2017.

RONDINELLI, R. C. O documento arquivístico ante a realidade digital: uma revisão conceitual necessária. Rio de Janeiro: Fundação Getúlio Vargas, 2013.

ROCHA, R. O videogame como documento arquivístico: reflexões sobre o estado da arte. 2016. Trabalho de Conclusão de Curso (Graduação em Arquivologia) - Faculdade de Arquivologia, Universidade Federal do Estado do Rio de Janeiro, Rio de Janeiro, 2016.

SANTAELLA, L.; FEITOZA, M. (Orgs.). Mapa do jogo: a diversidade cultural dos games. São Paulo: Cengage Learning, 2009. Disponível em: http://www4.pucsp.br/pos/tidd/teccogs/resenh as/2009/edicao_2/1-mapa_do_jogo- diversidade_cultural_dos_games-

ana_paula_narciso_severo-

guilherme_quintana-gilberto_tensai-

reynaldo_ramos.pdf Acesso em 20/02/2017

SANTOS JUNIOR, R. L. Preservação digital dos videogames: primeiras aproximações com a Arquivologia. In: NEVES, A. B.; ROCHA, M. M. V.; SILVA, P. (Org.). Cartografia da Pesquisa e Ensino em Arquivologia no Brasil: IV REPARQ. João Pessoa: Editora da UFPB, 2016, p. 578-607.

SANTOS JUNIOR, R. L.; NUNES, V. M. Estudo da preservação digital dos videogames sob o viés da Arquivologia. Informação \& Sociedade (UFPB. Online), v. 26, p. 31-46, 2016.

SHAW, A. What is video game culture? Cultural studies and games studies. Games and Culture, v.5, n.4, p.403-24, 2010.

SCHAFER, M. B.; CONSTANTE, S. E. Políticas e estratégias para a preservação da informação digital. PontodeAcesso, v. 6, p. 108-140, 2012.

THOMAZ, K. P. Gestão e preservação de documentos eletrônicos de arquivo: revisão de literatura - parte 2. Arquivística.net, v. 2, n.1, p. 114-131, 2006.

VALLE, E. Sistemas de informações multimídia na preservação de acervos permanentes. Dissertação (Mestrado em Ciência da Computação) - Universidade Federal de Minas Gerais, 2003. Disponível em:

http://www.eduardovalle.com/permalink.htm? doc $=$ doc00001> Acesso em 25/01/2016

WHEDBEE, K. E. Preservation, Restoration, and Accessibility of Popular Culture Materials. In: BURNS, G. (org.) A companion to popular culture. West Sussex: Jon Willey \& Sons, 2016, p.63-81.

WINGET, M. A.; MURRAY, C. Collecting and Preserving Videogames and Their Related Materials: A Review of Current Practice, Game-Related Archives and Research 
Projects. ASIS\&T Annual Meeting, 2008. Disponível em: arxiv.org/pdf/0811.3137 acesso em 25/04/2016.

ZANAGA, Mariângela Pisone; LIESENBERG, Hans Kurt Edmund. Autoria e compartilhamento social: a criação de conteúdos na internet. DataGramaZero Revista de Ciência da Informação. V.9 n.1., $2008 . \quad$ Disponível em http://www.dgz.org.br/fev08/F_I_art.htm /acesso em 20/08/2015 